\title{
A TRADUÇÃO DE JOHN DEWEY NA COLEÇÃO AUTORAL BIBLIOTECA DA EDUCAÇÃO*
}

\author{
Maria Rita de Almeida Toledo ${ }^{1}$ \\ Marta Carvalho $^{1}$
}

RESUMO: O artigo analisa o regime de tradução de textos de John Dewey efetuada por Anísio Teixeira, na Biblioteca de Educação (BE), dirigida por Lourenço Filho. Para tanto, descreve-se a materialidade dessa coleção autoral, distinguindo sua fórmula editorial, que instaura, pelo menos em parte, o regime de traduçáo no qual se processam os textos vertidos para o português. Tal operação historiográfica permite analisar as estratégias de seu editor para atingir os leitores destinatários e apresentar saberes a serem difundidos no campo educacional em um período de disputas de sua (re)configuração. Para tanto, analisamse os volumes da coleção, as ediçôes estadunidenses desses textos e a correspondência entre os editores.

Palavras-chave: Biblioteca de Educação. Regime de tradução. John Dewey.

\section{THE TRANSLATION OF JOHN DEWEY IN THE AUTHORIAL COLLECTION BIBLIOTECA DE EDUCAÇÃO}

ABSTRACT: The paper analyses the translation arrangements of John Dewey's texts made by Anísio Teixeira, in the Biblioteca de Educação (BE), headed by Lourenço Filho. It describes the materiality of this authorial collection, distinguishing its editorial formula which establishes, at least partially, the translation arrangements of texts poured into Portuguese. Such historiographical operation allows to analyze the strategies assumed by the editor to reach readers and to present knowledge to be disseminated in the polemical reconfiguration of educational field. It analyses the volumes of the collection, the American editions of the texts and the editors' correspondence.

Keywords: Biblioteca de Educação. Translation arrangements. John Dewey.

\footnotetext{
*Este artigo é resultante de dois projetos de pesquisas: "Imprensa, circulação de modelos pedagógicos e representações do aluno e do professor das escolas primárias paulistas (1893-1936): da pedagogia como arte de ensinar à pedagogia da escola nova" e "Traduçôes culturais da obra de John Dewey nas coleçôes autorais da Companhia Editora Nacional (1933-1981)", com financiamento da Capes e do CNPq. ${ }^{1}$ Universidade Federal de São Paulo - São Paulo (SP), Brasil.

DOI: 10.1590/ES0101-73302017157307
} 


\section{LA TRADUCTION DE JOHN DEWEY DANS LA COLLECTION D'AUTEUR BIBLIOTECA DE EDUCAÇÃO}

RESUMÉ : L'article analyse les modalités de traduction des textes de John Dewey faites par Anísio Teixeira, en Biblioteca de Educação (BE), dirigée par Lourenço Filho. On décrive ainsi la matérialité de cette collection de l'auteur en distinguant sa formule éditoriale qui établit, partiellement au moins, les modalités de traduction des textes versés en Portugais. Cette opération historiographique permet d'analyser les stratégies adoptées par l'éditeur pour atteindre ses lecteurs et de présenter les savoirs à être diffusés dans le domaine éducationnel pendant une période de débat autour de sa (re)configuration. On analyse les volumes de la collection, les éditions américaines de ces textes et la correspondance entre les éditeurs.

Mots-clés : Biblioteca de Educação. Modalités de traduction. John Dewey.

\section{Introdução}

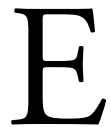

ste artigo tem como objetivo analisar o regime de traduçáo (BURKE; HSIA, 2009) dos textos de John Dewey, "The Child and the Curriculum" (1902) e "Interest and Effort in Education" (1913), efetuadas por Anísio Teixeira, na Biblioteca de Educação (BE), dirigida por Lourenço Filho.

A edição de traduçóes em coleçôes de livros tem uma especificidade: sua publicação em volumes de uma coleção produz, para além da operação linguística de versão do texto original, alteraçôes de sentido que não devem ser subestimadas. A intervenção do que Chartier $(1990 ; 1994)$ chama de "dispositivos editoriais e textuais de modelização da leitura" - como a escolha de um padrão de cobertura (capa, lombada, quarta-capa), de estruturaçáo interna e de estratégias de divulgaçáo - opera a padronizaçáo dos volumes publicados, produzindo a identidade da coleção. Mas é principalmente o que Olivero (1999) chama de "aparelho crítico" - prefácios; notas do tradutor ou do editor e comentários introduzidos nos volumes; índices remissivo e onomástico; exercícios; sumários, etc. - que produz alteraçôes de sentido nos textos traduzidos e publicados.

Destaca-se ainda que a dinâmica de produção de coleções é afeita a associaçóes de projetos prescritivos de formação de leitores, porque estabelece uma determinada ordem para as leituras - de sequência; de combinação de autores e de conteúdos - mas também pela sua capacidade didática, inscrita nos dispositivos materiais e tipográficos dos textos nela impressos. Além disso, ao se adotar um nome de destaque para a direçáo-geral de uma coleção, sua fórmula editorial passa a ser autoral, porque articula a autoridade do diretor ao programa de leituras nela publicado (TOLEDO, 2013). Nessa perspectiva, a fórmula editorial da coleção 
instaura, pelo menos em parte, o regime de tradução no qual se processa e circula o texto vertido para outra língua (TOLEDO, 2013). Portanto, é fundamental a análise da materialidade do impresso.

$\mathrm{Na}$ análise das práticas de tradução e publicação dos textos de Dewey, é de fundamental importância identificar critérios de escolha e/ou composição dos títulos traduzidos, interrogando-se sobre as estratégias editoriais que os colocaram em circulação, de modo a compor o seu lugar na geografia cultural instaurada pela fórmula editorial da coleção; mas, também, atentando-se para as redes interpessoais e interinstitucionais que facilitaram a circulação internacional dos saberes pedagógicos. As traduçôes são tomadas como "traduçôes culturais": "um duplo processo de descontextualização e recontextualizaçáo que primeiro busca se apropriar de algo estranho e em seguida o domestica" (BURKE; HSIA, 2009, p. 14). Complementarmente, é importante analisar a apropriação que é feita desses textos, quando são traduzidos e publicados em situaçóes culturais distintas das que presidiram sua produção original, desvelando o seu regime de tradução (BURKE; HSIA, 2009).

\section{A Biblioteca de Educação}

A BE foi publicada entre 1927 e 1970, editando 37 títulos e diversas reedições, sob o selo Cia Melhoramentos de São Paulo.

Desde meados dos anos 1910, a Weisflog e Irmáos, editora que deu origem à Melhoramentos, associou-se ao campo educacional, convidando educadores ligados à renovação dos materiais escolares, como Arnaldo Barreto, para produzirem sob o seu selo (DONATO, 1990, p. 51). A Editora investiu no mercado educacional, procurando atender a demandas da escola e das políticas educacionais instauradas pelo governo paulista. Por essa estratégia, convidou Lourenço Filho - "especialista bastante conhecido"1 -para dirigir uma nova coleção de livros destinada, sobretudo, aos professores, na vaga aberta pelas discussóes que se intensificavam em São Paulo sobre a melhoria da formação docente (NAGLE, 1960). Com o nome de Lourenço Filho, a Editora chancelava o novo empreendimento e garantia, avalizada pelas relaçóes desse educador no campo educacional, o acesso a um elenco de especialistas com o qual poderia alargar o seu rol de novos autores.

A própria Editora apresenta a $\mathrm{BE}$ como uma iniciativa que deveria suprir a "falta" de material disponível no mercado:

Dada a deficiência (para não dizer já a ausência) de livros com esse escopo [livros concisos e claros sobre as bases científicas da educação e seus processos racionais], em língua nacional, achamos que a iniciativa vem ao encontro de uma de nossas necessidades de divulgaçáo cultural, devendo encontrar por isso, boa acolhida dos estudiosos. (FOLHETO DE PROPAGANDA DA BIBLIOTHECA DE EDUCAÇÃO, 1927) 
O novo editor optou, entre 1927 e $1940^{2}$, por um programa de leitura formado por autores brasileiros e traduçóes, em brochuras de pequeno formato, dotadas de um desenho de capa clássico, do tipo francês, comumente encontrado nas prateleiras das livrarias. Essa opção barateava o preço dos volumes, acomodando-os aos salários do público destinatário: o professor ${ }^{3}$. Em cada um dos livrinhos, um pequeno texto do editor descrevia a organização da Coleção ${ }^{4}$, acompanhado pela lista dos títulos já publicados e dos futuros lançamentos, do preço e dos endereços de contato da Editora.

Nessa apresentação, o editor explicitava os leitores destinatários e os critérios de seleção dos textos, destacando que a BE seria indispensável aos "srs professores, normalistas e srs paes em geral, directamente interessados em conhecer as bases scientificas da educação e seus processos racionaes" (PIÉRON, [1927]). Nesse mesmo texto, informava que cada volume conteria "sempre um assunto completo e a coleção toda se distinguiria por duas séries, uma das bases científicas do ensino, outra de aplicaçóes práticas e crítica de sistemas” (PIÉRON, [1927]).

A fórmula editorial da coleção contava com um minucioso "aparelho crítico" (OLIVERO, 1999): prefácios, notas de tradução e do editor, sistema de remissão dos assuntos tratados a outras publicaçóes e sistema de classificação dos volumes publicados relativamente a temas e questóes de pedagogia. Esse aparelho crítico funciona como protocolo de leitura e como dispositivo de validação da autoridade da autoria e dos títulos publicados, além de didatizar os conteúdos editados. Sobretudo nos prefácios, assinados em sua maioria por Lourenço Filho, o editor tecia o intertexto que unificava os diferentes volumes, mobilizando informaçóes que credenciavam os seus autores e legitimavam os saberes neles compendiados, prescrevendo um modo peculiar de entendimento dos contornos do campo da pedagogia que difundia5 (CARVALHO; TOLEDO, 2006).

No protocolo de leitura dos comentários de divulgação dos volumes impressos na quarta capa, as traduções e os textos de brasileiros são situados, de maneiras distintas, na geografia cultural organizada pela coleção: as traduçóes eram tratadas exclusivamente como fontes dos aspectos "científicos do conhecimento" que deveriam compor a nova pedagogia proposta na $\mathrm{BE}$; enquanto os textos de brasileiros, pelo que se pode inferir, destinavam-se tanto a apresentar as "bases científicas do ensino, quanto para os meios práticos de educação e ensino" (CARVALHO, 2003; CARVALHO, 2000) ${ }^{6}$. Um dos dispositivos fundamentais da BE era o da distribuição entre os autores, de maneira a organizar para o leitor o modo como deveria se apropriar dos saberes pedagógicos difundidos, sempre tendo em vista as condiçóes específicas de sua aplicação no Brasil. Nessa repartição do campo dos saberes pedagógicos, o programa de leitura da BE é iniciado com dois títulos cujos conteúdos deveriam proporcionar ao leitor os rudimentos de psicologia experimental e de pedagogia experimental, na palavra autorizada de duas figuras de renome no cenário internacional: Henri Piéron e Edouard Claparède. Na pequena síntese de divulgação desses títulos, na quarta capa dos volumes, lê-se: 
I. PSYCHOLOGIA EXPERIMENTAL - por Henri Piéron - Indispensável aos srs. Professores, como exposição geral dos problemas e dos méthodos da psychologia moderna. Toda a II parte é dedicada aos "testes"

II. A ESCOLA E A PSYCHOLOGIA EXPERIMENTAL, por Ed. Claparède - verdadeira iniciaçáo ao estudo da pedagogia experimental. (quarta-capa do volume XVIII da Biblioteca de Educação)

O leitor encontraria, no programa da Biblioteca, um mapa norteador que lhe daria acesso ao que o editor considerava serem as mais modernas tendências do movimento pedagógico internacional. Para facilitar esse acesso, a BE se organizava segundo critérios derivados das representaçóes que o editor tinha do seu público leitor, adequando a exposição com o recurso a dispositivos tipográficos e textuais que levassem em conta o que o editor entendia serem as disposiçóes e competências de leitura específicas desse público. Triadas pelos crivos avaliativos do editor, as proposiçóes da chamada "pedagogia da escola nova" foram difundidas pela Coleção. Nesse sentido, é importante pensar a BE como produto de uma estratégia editorial destinada a promover uma nova cultura pedagógica do professorado, mudando sua "mentalidade" . Nessa estratégia, a coleção funcionou como dispositivo eficaz de fixação do sentido do "novo", no cipoal das proposições pedagógicas que, concorrentemente, reivindicavam para si, por todo o país, o estatuto

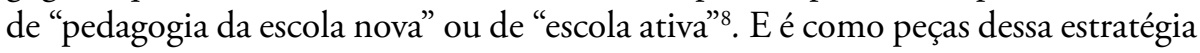
que devem ser examinadas as escolhas do editor de títulos e autores estrangeiros, assim como o tratamento editorial que deu às traduçôes editadas.

Os autores brasileiros se sobrepuseram em número, na composição da BE, às traduções. Lourenço Filho reuniu autores que integraram sua rede de relaçóes ao longo de sua trajetória política de especialista em educação. Enquanto Lourenço Filho ascendia no cenário educacional do Estado de Sáo Paulo, entre os anos de 1927 e 1930, editou autores ligados a ele, como Firmino Proença e Sampaio Dória, seus companheiros na Sociedade de Educação; ou professores de importantes instituições de ensino desse Estado, como H. Geenen, do Ginásio de Ribeirão Preto, ou Octavio Domingues, da Escola Superior de Agricultura Luiz de Queiroz. Após 1931, com a sua mudança para o Rio de Janeiro, as escolhas do editor recaíram sobre as figuras ligadas a instituições cariocas e ao movimento educacional organizado pela Associação Brasileira de Educação (ABE), como Venâncio Filho, Jonathas Serrano, Ariosto Espinheiro, M. A. Teixeira de Freitas, entre outros.

Quanto ao perfil dos autores traduzidos ${ }^{9}$, Lourenço Filho optou claramente pelos reconhecidos no movimento internacional pela Escola Nova, que vinham sendo difundidos especialmente na Europa, como Claparède, Ferrière, Piéron, Binet e Luzuriaga. A referência ao debate europeu marcou a $\mathrm{BE}^{10}$. Lourenço Filho foi, no período que coincide com a edição dos primeiros volumes da Coleção, 
o correspondente brasileiro do Bureau International d'Éducation (1928), além de ter se relacionado pessoalmente com figuras importantes da Ligue Internationale pour l'Éducation Nouvelle ${ }^{11}$, como Ferrière e Piéron. As relaçóes de Lourenço Filho com esse movimento, por sua vez, estabeleceram-se, principalmente, a partir de lugares de sociabilidade constituídos no Brasil, mais especificamente em São Paulo, onde havia nascido e vinha trilhando sua carreira profissional. Desde o início da década de 1920, ele integrava um círculo de educadores, editores, jornalistas e escritores nucleados em torno da empresa jornalística $O$ Estado de S. Paulo. É desse círculo que brota a iniciativa de lançamento do Manifesto dos Pioneiros da Educação Nova, de que foi signatário. Será nesse circuito que serão estabelecidas redes de relações com o Grupo Francês da Educação Nova, vinculado à Ligue Internationale pour l'École Nouvelle, notadamente com Henri Piéron e Paul Fauconnet ${ }^{12}$, o prefaciador do volume $\mathrm{V}$ da BE, Educação e Sociologia, de Émile Durkheim. Piéron e Fauconnet vieram a Sáo Paulo no final dos anos 1920, convidados para proferir conferências para esse círculo de intelectuais, no âmbito de iniciativas ligadas ao Consulado francês. É nesses anos, mais precisamente em 1927, que Lourenço Filho começa a organizar, para a Melhoramentos, a sua coleção, iniciando-a com o livro de Piéron, Psicologia Experimental, de que é o tradutor e o prefaciador.

Mas Lourenço Filho editou autores norte-americanos, da Columbia University, não deixando de fora duas importantes referências: Dewey e Kilpatrick. Contudo, essas escolhas ainda parecem nascer das partilhas de suas relaçóes pessoais. No final dos anos 1920, Anísio Teixeira - amigo de Monteiro Lobato, também membro do círculo do Estadão (AZEVEDO; CAMARGO; SACHETA, 1997) - acabara de retornar de viagem de estudo aos Estados Unidos, onde frequentara a Columbia University e se cativara pela pedagogia deweyana. Voltara dessa viagem convencido de que o pensamento de Dewey sintetizava o então "atual sentido da educação". Como Diretor de Instrução Pública na Bahia, faz distribuir o seu Relatório de Viagem - Aspectos Americanos de Educação (1928), no intuito pedagógico de "despertar um interesse concreto pela revisão de nossas próprias concepçóes" educacionais, apresentando "em um breve resumo tão fiel quanto... possível as idéias com que Dewey fixa o atual sentido de educação" 13 . Esse entusiasta propagador da pedagogia deweyana será escolhido por Lourenço Filho para ser o responsável pela seleçáo, tradução e edição dos textos de autoria do educador norte-americano para a $\mathrm{BE}$, além de mediar os contatos estabelecidos com os editores responsáveis pelos direitos de tradução dessa obra.

\section{John Dewey na Biblioteca de Educação}

As negociaçóes entre Teixeira e Lourenço Filho para a edição do novo livrinho aparecem em carta de novembro de 1929, na qual Lourenço Filho comenta: 
Muito me alegrou a nova de que V. dará logo as traduçóes de Dewey. Creio que os dois primeiros trabalhos, e o seu prefácio, darão um optimo volume, de 120 a 150 páginas. Desenvolva esse prefácio, de modo a podermos mesmo dar o título ao volume de "A Pedagogia de John Dewey", ou coisa semelhante. Será assim um trabalho de creação sua, também, e, possivelmente, a publicar-se antes do concurso. (LOURENÇO FILHO, 1929)

É preciso destacar que a escolha de Dewey para integrar a coleção vem em uma conjuntura bastante especial para Lourenço Filho. Na mesma carta, ele fala sobre seu interesse:

(...) As informaçóes da Columbia muito me interessam. Tanto mais que estou com plano de um trabalho, para o anno próximo, que envolve a creaçáo de um "instituto de educação" - uma coisa que seja um desenvolvimento de meus cursos na escola normal, para professores já formados. É preciso doutrinar... Creio já vencida, em parte, a phase de propaganda das novas idéas e agora pretendo dar corpo a certos trabalhos de realisaçáo de pedagogia experimental. A lucta não será pequena, mas o prazer está justamente no ardor que ella exige. Precisamos ir combatendo, sem treguas, os espírito romantico de nossa gente... (LOURENÇO FILHO, 1929) ${ }^{14}$

Entre os textos de Dewey afeitos ao programa da BE, Teixeira buscava autorização para a tradução de, pelo menos, três deles: "Moral Principles in Education", "Interest and Effort" e "The Child and the Curriculum". Os dois primeiros eram ensaios que o autor havia apresentado em reunióes da National Herbart Society, no final do XIX ${ }^{15}$, e tinham aparecido, em 1905 e 1913, como os dois primeiros volumes da coleçáo dirigida por Henry Suzzallo, "The Riverside Educational Monographs", na série "General Education Theory", voltada para a formaçáo docente. $\mathrm{O}$ terceiro era um texto publicado pela University of Chicago Press (1902). Escrito dois anos antes de Dewey deixar essa universidade, The Child and the Curriculum é considerado por Kliebard (2004) como a mais conhecida e a mais clara exposição da teoria deweyana sobre currículo, provocada pelos debates sobre o assunto, que vinham sendo travados, já havia alguns anos, na National Herbart Society. Essa teoria é produto da experiência do autor à frente da escola-laboratório da Universidade de Chicago e do modo como, naquela instituição, havia organizado o currículo, contrapondo-se a alguns dos postulados herbartianos ${ }^{16}$.

No final de 1929, Teixeira escreve para Suzallo, perguntando sobre a possibilidade de traduzir e editar os textos de Dewey de sua coleção. A resposta vem logo no início de 1930:

I have your note of inquiry with regard to permission to translate Dewey's Interest and Effort and Moral Principles in Education, parts of which have been published by Houghton Mifflin Company (...), as monographs in the series of Riverside Editorial Monographs. 
As this is a matter which the editor does not handle, I am referring the same to the Educational Department of Houghton Mifflin Company and they will write you direct (SUZZALLO, 1930a).

Teixeira recebe, mesmo antes dessa carta de Suzzallo, uma outra da Houghton Mifflin Company, informando que os títulos procurados por ele não tinham sido traduzidos para o português:

Our New York house has forwarded to us your letter of the 27th ult. with reference to a Portuguese translation of Dr. John Dewey's two books "Interest and Effort" and "Moral Principles in Education" since all such matters are dealt with at the headquarters of the Company. Neither of these books has been translated into Portuguese, though they have been reproduced in French, German and Armenian. We are interested in your desire to include them in the series of monographs to be edited by Professor Filho, and shall be glad to authorize your so issuing them (HOUGHTON MIFFLIN CO., 1930).

Na mesma carta, a Editora propóe as bases dos negócios:

In the case of such translations we ask a nominal honorarium of fifty dollars for each book as a recognition of the author's rights. We should also be obliged if you would state in the book that the translation is authorized by the American publishers, Houghton Mifflin Company, and to receive a copy of translation when published for Dr. Dewey.

Kindly let us know if these terms are acceptable (...). (HOUGHTON MIFFLIN CO., 1930)

Teixeira escreve também para o Editor da University of Chicago Press para verificar a permissão e as condições de tradução de "The Child and the Curriculum". A resposta da editora vem no final de janeiro:

We are in receipt of your letter of December 27 and are writing to say that we have pleasure in giving you permission to translate Dewey's The Child and the Curriculum into Portuguese provided you are willing to conform to the following terms:

1. That arrangements be made with some good Portuguese publishing house and that such house write us proposing the publication of the translation.

2. That this publishing house pay us the nominal fee of $\$ 1.00$. 
3. That Dewey's name appear on the title page of the translation as author of original volume.

4. That in the preface or preliminary pages of the translation it be stated that the University of Chicago Press is the publisher of the original volume.

5. That the Portuguese publisher send us five copies of the completed translation.

6. These are the terms that we always make with those who are planning to translate any of our publications. If they are satisfactory to you, wil you kindly communicate with us? (LAING, 1930)

A resposta da University of Chicago Press, no final de maio, ainda pede que Teixeira apresentasse o projeto de publicaçáo dos textos para que o próprio Dewey pudesse examinar e aprovar a alteração da nova forma editorial dada a eles (Cf. LAING, 1930). Ao mesmo tempo, o educador parece continuar a pesquisa sobre os textos mais adequados para a BE: em carta, ainda no final de maio, recebe esclarecimentos de Suzzallo quanto aos textos já negociados com a Houghton Mifflin Company:

My dear Teixeira:

Replying to your letter regarding the Dewey Essays, which you are translating into the Portuguese, let me say that the two Houghton Mifflin publications - "Interest and Effort" and "Moral Principles in Education" are the same essays that were published by the University of Chicago press under the titles: "Interest as Related to the Will" and "Ethical Principles Underlying Education":

Professor Dewey re-wrote them for the purposes of clarity. None of the essencial argument is missing in either case. So you need not fear that any parts of the logic are omitted. The treatment is merely made longer or shorter for the purposes of easier reading by teachers. (SUZZALLO, 1930b)

Como se vê, Suzzallo parece querer convencer Teixeira a dar preferência às negociações com a Houghton Mifflin Company, explicando que as versóes publicadas nessa editora eram preferíveis às versóes anteriores ${ }^{17}$, pois teriam sido fruto de intervençóes de Dewey, que, sem alterar o encadeamento lógico das partes, teria facilitado os textos para professores. Recomenda a publicação dos dois textos de sua coleção. Embora Teixeira tenha acatado a sugestão de Suzzallo na escolha da versão de "Interest and Effort", ele prefere excluir o outro texto recomendado, para incluir "The Child and the Curriculum". 
É curioso que Teixeira tenha dado preferência a textos escritos por Dewey no final do século XIX e início do século XX em detrimento de textos mais recentes e contemporâneos a sua visita ao país. Embora seja impossível, nos limites deste artigo, explorar mais detalhadamente essa questão, pode-se aventar a hipótese de que os textos escolhidos preenchessem mais amplamente o critério determinado pelo imperativo de promover uma mudança radical no entendimento que os professores brasileiros tinham do trabalho pedagógico, incidindo sobre os pressupostos desse. A hipótese tem apoio no propósito, afirmado por Teixeira em seu Relatório de Viagem (1928), de expor nele as ideias de Dewey, no intuito de "fixar o 'sentido da educação que conhecera institucionalizada na América e criticar concepções então dominantes no Brasil de modo a 'despertar um interesse concreto pela (sua) revisão'” (CARVALHO, 2003; CARVALHO, 2000). Tal propósito coincidia, apesar de algumas discrepâncias, com o objetivo de Lourenço Filho de gradativamente promover por meio da BE uma mudança "no espírito do professorado quanto à filosofia do ensino" (CARVALHO, 2002).

A edição dos livros foi realizada em curtíssimo tempo e, no início de outubro de 1930, a nova obra de Dewey e de Teixeira - Vida e Educação - já estava nas prateleiras das livrarias de São Paulo e do Rio de Janeiro. Em carta, os editores anunciam:

Temos o prazer de informar a V. S. que acabamos de publicar o livro de Dewey, VIDA E EDUCAÇÃO, traduzido por V S e delle lhe enviamos (...) 10 exemplares. Procuramos dar à obra feição material digna do texto. Como autores dois nomes dos mais illustres na pedagogia, certamente elle se imporá ao magistério dos paiz, garantindo assim grande sucesso de livraria. (CIA. MELHORAMENTOS, 1930)

\section{A feição material de Vida e Educação}

Como já indicado, as escolhas de Teixeira recaíram sobre "The Child and the Curriculum" e "Interest and Effort", ficando de fora o outro texto, "Moral Principles in Education". O livrinho obviamente tinha a mesma capa dos outros volumes e foi publicado imediatamente após o título de Lourenço Filho - Introdução aos Estudos da Escola Nova - como número 12.

Em sua folha de rosto, eram cumpridas as regras dos contratos com as editoras vendedoras dos direitos de tradução: comparecia o novo título de Dewey, seguido dos subtítulos "I - A criança e o Programa Escolar; II - Interesse e Esforço"; o nome de Dewey, com sua filiação institucional (Professor de Filosofia, na Universidade de Columbia, Nova York); e o destaque para a tradução e o estudo preliminar da pedagogia do autor, seguido do nome de Anísio Teixeira e sua filiação 
institucional (Prof. de Filosofia da Educação, no Instituto de Educação do Rio de Janeiro). Desse corpo de informaçóes, é importante notar que os nomes do autor e do tradutor estavam impressos com o mesmo tamanho de letra, permanecendo na mesma condição autoral, materializando aquilo que Lourenço Filho havia destacado na já citada carta a Teixeira: "Será assim um trabalho de creação sua".

O volume, como todos os outros da coleção, era composto por uma foto do autor, sua assinatura sobre ela, e o prefácio de Lourenço Filho, intitulado "Dewey e a Pedagogia Americana". Na primeira parte, Lourenço Filho explica ao leitor o porquê do nome que deu ao seu próprio texto, indicando a importância de Dewey e sua obra nas mais diferentes reformas educacionais dos mais diferentes países. Destaca a importância da própria escolha do nome do autor no programa de leitura da BE e, seguindo a "lógica da falta", mostra que a única tradução de Dewey no Brasil fora impressa em um pequeno folheto da União Pan-Americana. Abre, então, todo um parágrafo para destacar os diferenciais do volume de Dewey por ele publicado:

Por isso mesmo, a Biblioteca da Educação não quis apresentar a versão simples dos interessantes trabalhos que se lerão a seguir, nem a entregou a qualquer ledor da língua inglesa, embora hábil: foi pedí-la a um antigo discípulo de Dewey, o dr. Anísio Teixeira, solicitando-lhe ao mesmo tempo que fizesse acompanhar de uma visão geral das teorias do mestre. E não errou. Além de uma traduçáo meticulosa, quanto à intenção de cada termo, Anísio Teixeira nos dá substancioso estudo acerca das idéias de Dewey e de Kilpatrick, dois dos lumiares da educação renovada nos Estados Unidos (...) (LOURENÇO FILHO in: DEWEY, [1930], p. 6)

Nessa passagem, Lourenço Filho, além de qualificar as escolhas que fez de autor, obra e tradutor, dá ao trabalho do tradutor o estatuto de autoria, indicando que a reinvenção do texto na língua portuguesa deve-se à autoridade de Teixeira, constituído como um "antigo discípulo de Dewey". Baliza e reforça o protocolo de leitura construído por Teixeira em seu estudo introdutório.

$\mathrm{Na}$ segunda parte do prefácio, o editor remete ao volume de sua autoria - "Introduçáo dos Estudos a Escola Nova" -, que acabara de ser publicado, o que o constitui como dispositivo de modelizaçáo de leitura do texto deweyano e como peça fundamental do aparelho crítico da Coleção. É importante observar que, no volume de Lourenço Filho, um procedimento de hierarquização reparte os sistemas de aplicação científica expostos nas liçóes III e IV dos sistemas de experimentação e ensaio expostos na lição II. Os autores dos primeiros são Montessori, Decroly e Dewey. Montessori e Decroly são tratados em um mesmo capítulo e Dewey merece um capítulo à parte. Para diferenciar esses sistemas dos anteriores, induzindo o leitor a preferi-los, Lourenço critica os "excessos" dos sistemas de 
experimentação e ensaio. Tratava-se de caracterizar a diferença dos "sistemas de mais rigorosa aplicação científica": neles eram evitados os exageros dos anteriores, caracterizados por uma "didática absenteísta", que deixa a criança entregue a si mesma, ou por um "espírito experimentalista", que transforma a escola em um laboratório permanente (LOURENÇO FILHO, 1930, p. 156) ${ }^{18}$.

$\mathrm{Na}$ terceira parte do prefácio de Vida e Educação, Lourenço Filho apresenta uma pequena biografia de Dewey, falando das instituiçóes pelas quais passou. Além disso, indica textos do autor, apresentando Dewey como uma das maiores figuras da educação norte-americana.

Esse prefácio é seguido do estudo introdutório de Teixeira, intitulado "A Pedagogia de Dewey (Esbôço da teoria de educação de John Dewey)", que ocupa um quarto do volume, destacando-se, portanto, ao lado do próprio texto traduzido.

O estudo de Teixeira é dividido em duas partes: I- Educação como reconstrução da experiência; II- A escola e a reconstrução da experiência. Por sua vez, cada uma dessas partes é organizada por meio de palavras-chave ou conceitos destacados em negrito no início dos parágrafos, sempre iniciando o assunto. Desse modo, o uso do negrito funciona como roteiro de leitura. Há um amplo uso do itálico para termos ou enunciados que teriam sido retirados dos textos usados para a construção do estudo ou para termos que deveriam ser ressignificados pelas novas teorias pedagógicas de Dewey. Os termos "conceito de experiência”, "processo de experiência”, "experiência educativa”, "conceito de educação" e "educação como necessidade da vida social" sáo algumas dessas palavras-chave em itálico que vão compondo um protocolo de leitura. Além disso, nesse mesmo estudo, há o emprego de notas de rodapé, seja para indicar a fonte de citaçóes diretas do autor, seja para esclarecer alguma opinião de Teixeira. Assim, a feição material da obra é engendrada sobre o uso de tipos diferenciados, conformando, já na visualidade do texto, um protocolo de leitura da pedagogia deweyana.

Procedimentos similares serão utilizados nos textos de Dewey publicados no volume. Comparando-as com os editados nos Estados Unidos, é possível observar uma notável diferença entre essas duas versóes no que diz respeito à forma material em que os textos são apresentados ${ }^{19}$. Tanto no texto editado pela Houghton Mifflin Company como no editado pela University of Chicago Press não há nenhum uso de dispositivos de leitura que destaquem ou diferenciem termos ou enunciados, para além das aberturas de capítulo, com seus respectivos títulos, e do uso de parágrafos e pontuação.

O texto "The Child and the Curriculum", na versão impressa pela University of Chicago Press, não contém partes ou divisões de capítulos. O livro usa apenas a divisão de parágrafos, estabelecida, provavelmente, pelo próprio autor em seu manuscrito. Já na versão traduzida, "A criança e o programa escolar", o 
texto passa a conter 18 partes numeradas e nominadas, como no estudo introdutório, por meio de palavras-chave/conceitos em negrito, demarcando certa ênfase de leitura: "1. Os dissídios teóricos"; "2. Elementos fundamentais do processo educativo"; "3. O mundo infantil"; "4. O mundo escolar"; "5. Soluçôes diversas"; "6. Disciplina contra interesse"; "7. Necessidade de conciliação"; "8. Importância do problema"... Como se vê, a versão traduzida altera radicalmente a disposição material do texto, ao introduzir a notação de números e títulos para o que o tradutor/editor entendeu serem subpartes dos capítulos do original de Dewey. As subpartes vão roteirizando a leitura, de modo a conduzir o leitor no emaranhado dos termos usados por Dewey, demarcando pausas na leitura e facilitando-a, ao entrecortar as longas consideraçóes originais do autor. Tais intervençóes tipográficas na materialidade do texto original complementam-se por dispositivos textuais: inúmeras notas do tradutor pontuam o texto traduzido, remetendo a outras leituras capazes de fornecer novos códigos de leitura. Entre elas, especialmente as referências ao volume "Introdução aos Estudos da Escola Nova”. Recorrendo a esses dispositivos de modelização e facilitação da leitura, editor e tradutor fazem uma opção de adequação do texto a um novo público, deixando evidentes suas representaçóes sobre as competências de seu leitor destinatário e o seu cuidado em garantir que esse leitor se apropriasse de forma adequada dos novos preceitos pedagógicos que o volume e a coleção difundiam.

Com o texto "Interest and Effort" se passa algo um pouco diferente, apesar do uso das redivisóes de parágrafos e da introdução de notas do tradutor. Como se viu, o texto usado para tradução já tinha sido objeto de intervençôes do próprio Dewey, que, segundo Suzzallo, alterou o texto original, adequando-o à leitura de professores, tornando as intervençóes do tradutor menos necessárias. Diferentemente de "The Child and the Curriculum", "Interest and Effort" está organizado em cinco capítulos, acrescidos de uma introdução do editor e um "Outline” - espécie de temário encontrado em cada um dos capítulos - que funcionava como dispositivo facilitador da leitura. Na versão traduzida, essa introdução do editor é eliminada. No caso do "Outline”, os itens constantes do temário se transformam em subdivisóes introduzidas em cada um dos capítulos. Nesse novo formato, há, comparativamente ao primeiro texto, uma reorganização menos radical do texto original, operada apenas por meio de dispositivos de leitura que transformam os títulos de capítulos em títulos de parágrafos.

Vida e Educação é livro diverso de todos os que Dewey colocara no mercado, seja pela combinação dos textos que reúne - os de Dewey, de Lourenço Filho e de Anísio Teixeira -, seja pela fórmula material empregada. Produto de uma conjuntura específica, o volume reinventa a pedagogia de Dewey, transformando seus escritos em textos destinados a um leitor dotado de competências, disposiçóes e expectativas de leitura distintas - o professorado brasileiro dos anos 1930. 


\section{Considerações finais}

Analisamos a tradução como uma prática dotada de "negociação e renegociação" entre diferentes culturas, em que os tradutores e editores são espécies de mediadores da inteligibilidade entre elas, entre diferentes espaços e tempos (BURKE; HSIA, 2009). Procuramos evidenciar como, nas práticas de tradução dos textos de Dewey para a BE, as alteraçóes de sentido produzidas decorrem de operaçóes textuais e tipográficas que dão a ver as representaçóes do editor e do tradutor sobre as disposiçóes, as expectativas e as competências de seu público leitor. Essas alteraçóes também decorrem das representaçóes desses mediadores culturais sobre a situação educacional do país e sobre os requisitos necessários à mudança que gradativamente programaram promover "no espírito do professorado quanto à filosofia do ensino". Promover essa mudança era, sem dúvida, intervir culturalmente, levando o professor a uma nova compreensão das "finalidades sociais" da escola. Mas era ainda fazer esse professor percorrer o caminho que levaria à superaçáo de suas velhas concepções sobre a criança e sua atividade. $\mathrm{Na}$ conjunção desses objetivos é que ganhava corpo o programa de mudança da "mentalidade" do professor, acalentado por Lourenço Filho, Teixeira e seus parceiros no embate pela renovação da escola brasileira nos últimos anos da década de 1920 e no início da década de 1930.

\section{Notas}

1. Essa é a expressão usada por Lourenço Filho no folheto de propaganda da Coleção.

2. O recorte temporal 1927-1940 se sustenta a partir de critérios de periodização que foram discutidos em Carvalho e Toledo (2006).

3. Segundo Monarcha (1997), o preço dos livros, entre 1927 e 1941, variava entre $4 \$ 000$ e $10 \$ 000$, mas, na sua maioria, os livros custavam entre $4 \$ 000$ e $6 \$ 000$. Para o autor, esse preço era acessível ao bolso dos professores.

4. Esse texto encontrava-se na quarta capa e também no verso da página de espelho de cada volume.

5. Entre 1927 e 1955, todos os livros publicados na BE têm prefácios assinados por Lourenço Filho, com exceçâo de seus próprios títulos e três outros: "Temperamento e caráter sob o ponto de vista educativo", de H. Geenen, cujo prefácio é assinado por. Franco da Rocha; "Educação e Sociologia”, de E. Durkheim, cujo prefácio é assinado por Fauconnet; "Cinema e Educaçâo”, de J. Serrano e F. Venâncio Filho, cujo prefácio é assinado pelos próprios autores (CARVALHO; TOLEDO, 2006).

6. Assim, o título "A Hereditariedade em Face da Educação", de Octavio Domingues, por exemplo, era tido pelo editor como um magnífico apanhado das mais modernas teorias sobre o assunto e em especial o do 'mendelismo'; já “Como se ensina Geografia”, de Firmino Proença, era indicado como compendio de metodologia especializada para aplicação em cursos primário e secundário (O QUE É A BIBLIOTHECA..., 1934). 
7. A expressão é recorrente nos escritos de Lourenço Filho, indiciando a ambição e amplitude dos objetivos de seu programa de formação docente.

8. Ver, a respeito, Carvalho (2002).

9. Há um maior número de traduções entre 1927 e 1929, porém, as traduçôes jamais ultrapassaram o número de textos de autores brasileiros lançados anualmente. Cf. Monarcha (1997).

10.Monarcha (1997), em seu artigo sobre a Biblioteca, já havia notado essa peculiaridade nas escolhas de Lourenço Filho.

11.Sobre as relaçóes da Ligue International pour l'éducation nouvelle com os escolanovistas brasileiros, Cf. Carvalho, 2004.

12.Fauconnet foi professor na Sorbonne, onde lecionava, inicialmente, Psicologia e Pedagogia e, a partir de 1928, Ciências da Educação e Sociologia. Entre 1925 e 1931, presidiu o Grupo Francês de Educação Nova (G.F.E.N) e foi o redator para a França da revista Pour L'Ėre Nouvelle, cujo redator-chefe era Adolphe Ferrière. Conferir as informaçóes nas capas da revista Pour L'Ère Nouvelle publicadas no período.

13.Ver, a respeito, Carvalho, 2000.

14.A menção de Lourenço ao "espírito romântico de nossa gente" parece ecoar apreciaçóes críticas feitas sobre o espírito latino que Teixeira registra em seu diário de bordo disponível nos arquivos do CPDOC. Ver, a respeito, Carvalho, 2000.

15.A informação aparece nos volumes publicados por Suzzallo, na coleção Riverside Educational Monographs. Cf. http://archive.org

16.Ver Kliebard, 2004, especialmente o capítulo 3.

17.Tivemos acesso à versão de "Interest and Effort" publicada em 1895 pela University Chicago Press, no 1st Herbart Year Book, com o título "Interest as related to will".

18.Ver a respeito Carvalho (2002).

19.Utilizamo-nos das versôes digitalizadas dos textos "Interest and Effort" e "The Child and the curriculum" encontrados na biblioteca digital http://archive.org.

\section{Referências}

AZEVEDO, C.L.; CAMARGOS, M.; SACCHETTA, V. Monteiro Lobato: furacão na Botocúndia. São Paulo: Editora Senac, 1997.

BUREAU INTERNATIONAL D'ÉDUCATION. Bulletin n. 7. Pour L'Ėre Nouvelle, n. 37, p. 91, abr. 1928.

BURKE, P.; HSIA, R.P. (Orgs.). A tradução cultural nos primórdios da Europa Moderna. Sáo Paulo: Editora da Unesp, 2009.

CARVALHO, M.M.C. A Escola e a república e outros ensaios. Bragança Paulista: Edusf, 2003. 
. Anísio Teixeira: Itinerários. Contato, Brasília, v. 7, p. 85-103, 2000.

. O Manifesto e a Liga Internacional pela Escola Nova. In: XAVIER, M.C. $O$ manifesto dos pioneiros da Educaçáo Nova: Um legado educacional em debate. Rio de Janeiro: Fundação Getulio Vargas, 2004.

Pedagogia da Escola nova, produção da natureza infantil e controle doutrinário da escola. In: FREITAS, M.C.; KUHLMANN JR., M. (Orgs.). Os intelectuais na história da infância. Sáo Paulo: Cortez, 2002.

; TOLEDO, M.R.A. A Biblioteca da Educação de Lourenço Filho: uma coleção a serviço de um projeto de inovação pedagógica. Quaestio: Revista de Estudos de Educação, v. 8 , n. 2, 2006.

CHARTIER, R. A História Cultural: entre práticas e representaçóes. Lisboa/Rio de Janeiro: Difel/Bertrand, 1990.

. A ordem dos livros: leitores, autores e bibliotecas na Europa entre os séculos XIV e XVIII. Brasília: EUB, 1994.

CIA. MELHORAMENTOS. Carta do Editor Chefe a Anisio Teixeira. 3 out. 1930. CPDOC-FGV.

DEWEY, J. Interest and effort in education. Nova York: Hougton Mifflin Company, 1913. Disponível em <https://archive.org/details/interestandeffo00dewegoog >. Acesso em: 2 set. 2015.

The child and the curriculum. Chicago: Universitu of Chicago Press, 1902. Disponível

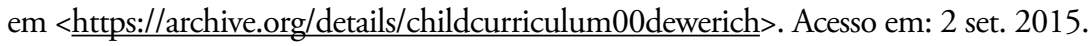

. Vida e educação. Tradução de Anísio Teixeira. São Paulo: Melhoramentos, [1930].

DONATO, H. 100 anos de Melhoramentos (1890-1990). São Paulo: Melhoramentos, 1990.

FOLHETO DE PROPAGANDA DA BIBLIOTHECA DE EDUCAÇÃO. São Paulo: Melhoramentos, 1927.

HOUGTON MIFFLIN CO. Carta a Anisio Teixeira. 21 jan. 1930. Rio de Janeiro: CPDOC-FGV.

KLIEBARD, H.M. The struggle for the American curriculum: 1893-1958. 3. ed. Nova York e Londres: Routledge Falmer, 2004.

LAING, G.J. Carta de G. J. Laing a Anisio Teixeira. 26 jan. 1930. Rio de Janeiro: CPDOC-FGV.

LOURENÇO FILHO, M.B. Carta a Anisio Teixeira. 1. ${ }^{\circ}$ nov. 1929. Rio de Janeiro: CPDOC-FGV.

Introdução aos estudos da Escola Nova: bases sistemas e diretrizes da pedagogia contemporânea. São Paulo: Melhoramentos, [1930]. v. XI.

MONARCHA, C. Lourenço Filho e a Bibliotheca de Educação (1927-1941). In:

(Org.). Lourenço Filho: outros aspectos, mesma obra. Campinas: Mercado de Letras/ Editora da Unesp, 1997.

NAGLE, J. A educação na primeira república. In: HOLLANDA, Sérgio Buarque de. História geral da civilização brasileira. São Paulo: Difel, 1960. Tomo 9. 
O QUE É A BIBLIOTHECA DE EDUCAÇÃO. São Paulo: Melhoramentos, [1934].

OLIVERO, I. L'Invention de la collection: de la diffusion de la littérature et des savoirs à la formation du citoyen au XIXe siècle. Paris: IMEC/Maison des Sciences de l'Homme, 1999.

PIÉRON, H. Psychologia experimental. São Paulo: Melhoramentos, [1927]. v. I.

SUZZALLO. Carta a Anisio Teixeira. 27 jan. 1930a. Rio de Janeiro: CPDOC-FGV.

. Carta a Anísio Teixeira. 29 maio 1930b. Rio de Janeiro: CPDOC-FGV.

TEIXEIRA, A. Aspectos americanos de educação: relatório apresentado ao Governo do Estado da Bahia pelo Diretor Geral da Instrução, comissionado em Estudos na América Bahia, Tip. São Francisco, 1928.

TOLEDO, M.R.A. Coleçôes autorais, traduçôes e circulação: ensaios sobre geografia cultural da edição (1930-1980). Tese (Doutorado em Livre Docência) - Departamento de História, Universidade Federal de Sáo Paulo, Guarulhos, 2013.

Recebido em 02 de dezembro de 2015.

Aprovado em 17 de outubro de 2016. 